\title{
Effect of Large Openings on the Behavior of Reinforced Concrete Continuous Deep Beams under Static and Repeated Load
}

\author{
Mohammed R. Khalaf ${ }^{1, a,{ }^{*}}$ and Ali Hussein A. Al-Ahmed ${ }^{1, b}$ \\ ${ }^{1}$ Civil Engineering Department, University of Baghdad, Baghdad, Iraq \\ am.khalaf1101@.coeng.uobaghdad.edu.iq, bdr.ali-alahmed@coeng.uobaghdad.edu.iq
}

\begin{abstract}
This paper aims to investigate the behavior of the existence of large openings on reinforced concrete continuous deep beams (RCCDBs) under static and limited cycles of repeated load. The experimental work included testing seven RCCDBs. One of these beams was solid subjected to static load, while the other beams having external shear spans, internal shear spans, and mid-span openings subjected to static and fifteen cycles of repeated loading. The range of the repeated loading was varied between a lower level and an upper level, equal to 30 and 70 percent, respectively, of the ultimate load of the beam subjected to static load. All test specimens were tested under five-point bending. For beams with large openings, $160 \times 160 \mathrm{~mm}$ (which represents $40 \%$ of the overall depth of the section) openings were created symmetrically at various locations. Experimental results showed that the maximum ultimate loads of beams with large openings were decreased by about $36 \%$ for beams with large openings locating at interior shear spans compared to a solid beam. However, the maximum reduction in ultimate load of the beam with a large opening subjected to repeated load was about $6 \%$.
\end{abstract}

Keywords: Continuous deep beams; large openings; static load; repeated load.

\section{Introduction}

In structural engineering experience, reinforced concrete continuous deep beam (RCCDB) is a subject of great interest [1-3]. The deep beam is one with a clear span (lc) to overall depth (H) ratio that is less than or equal to four [4]. Figure 1 shows an example of continuous deep beams. Openings in the web of continuous deep beams are commonly required to facilitate important services like water supply, electricity cables, telephone, and computer network and provide functionality such as doors and windows. The presence of openings such as in tubes and cables reduces the total shear strength of such beams, resulting in an increased deformation at ultimate strength. [2,3,6,7]. Mansur and Tan [6] classified the openings in reinforced concrete $(\mathrm{RC})$ beams as small or large. They recommended that an opening is considered large if the opening depth (ho) is greater than $25 \%$ of the overall depth of the section $(\mathrm{H})$. Apart from that, the opening may be described as small.

Openings in RCCDBs were never specified in the American Concrete Institute AC1318M-19. As a result, there is a great requirement for a safe, precise, and consistent design technique. Additionally, the existence of openings produces interruptions or disruptions in the normal flow of stresses. Loading on offshore structures, highways, and many other structures is often repeated in nature. Extensive theoretical and experimental studies of simply supported deep beams with or without openings over the years, well-established approaches for serviceability design under static loads have developed. [2, 3, 7-15]. However, the effects of repeated loading on RCCDBs are still rare and scarcely understood. Concrete structures subjected to repeated loading experience higher deflection comparing to those exposed to static loading. In this study, experimental investigations on the behavior of RCCDBs with large openings under five-point load have been carried out on continuous deep beams having large symmetrical openings subjected to static and limited cycles of repeated load. 


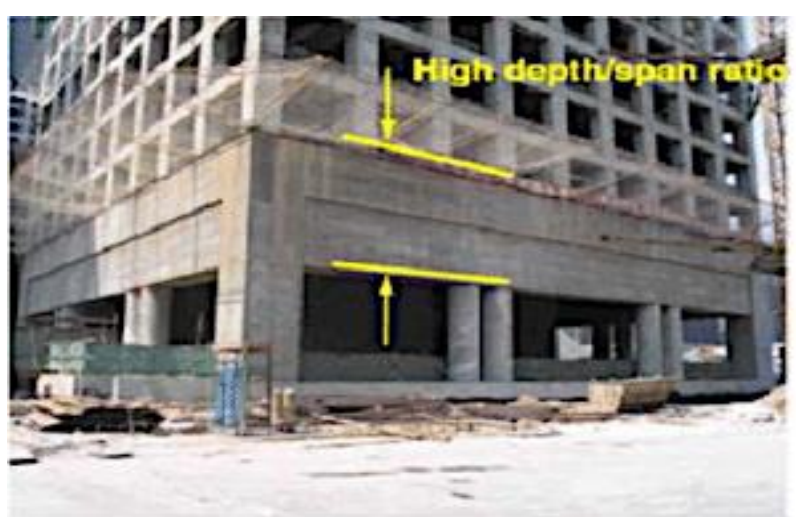

Figure 1. Photo picture of RCCDB [5].

\section{Experimental Program}

Descriptions of tested beams. The experimental work included testing seven RCCDBs under five-point bending. The tested specimens were $2500 \mathrm{~mm}$ overall length (clear span of $1190 \mathrm{~mm}$ ), $400 \mathrm{~mm}$ overall depth of beam, $160 \mathrm{~mm}$ width of the beam, and a shear span of $595 \mathrm{~mm}$ as shown in Figure 2. The first specimen (CDB-Solid) was prepared without opening (as a reference specimen). Openings of dimensions $160 \times 160 \mathrm{~mm}$ (representing $40 \%$ of the overall beam depth) were created in the remaining specimens. These openings were created symmetrically at the external shear spans, internal shear spans, and center of spans of the other specimens. The RCCDBs with openings were tested under static and repeated load. At the same time, beam CDB-Solid was tested under static load only. Table 1 summarizes the description of the tested beams.
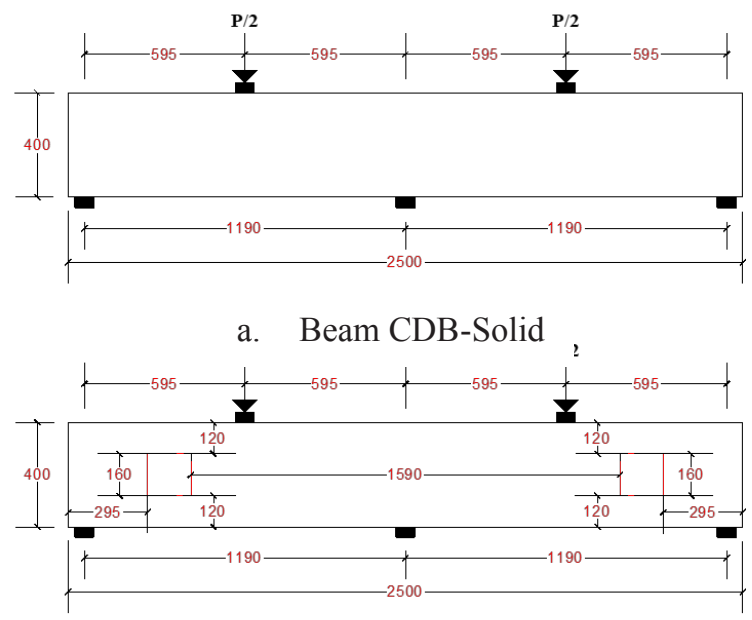

c. Beams CDB-M-EO and CDM-R-EO

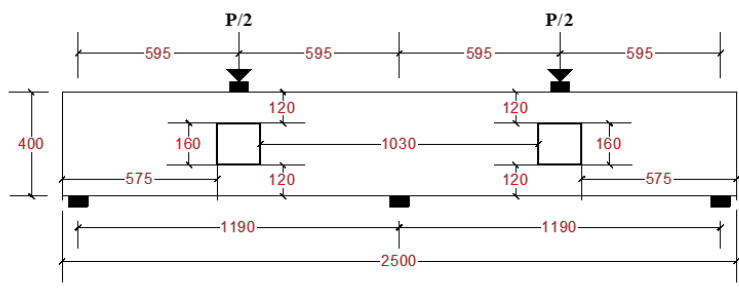

b. Beams CDB-M-MO and CDM-R-MO

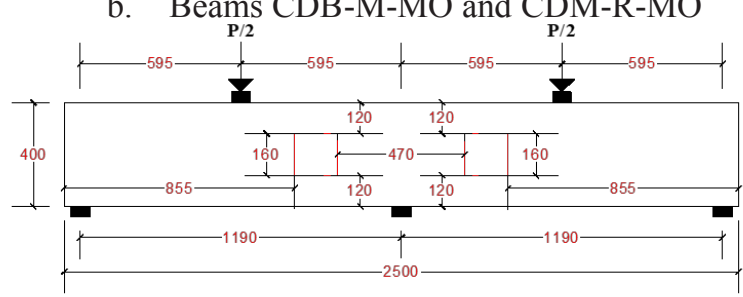

d. Beams CDB-M-IO and CDM-R-IO

Figure 2. Layout of typical experimental specimens (all dimensions are in $\mathrm{mm}$ ).

Table 1. Details of the tested specimens.

\begin{tabular}{cccc}
\hline $\begin{array}{c}\text { Specimen } \\
\text { nomenclature }\end{array}$ & Opening size $(\mathbf{m m})$ & Location & Type of application load \\
\hline CDB-Solid & --- & Solid & Static load \\
CDB-M-EO & $160 \times 160$ & External shear span & Static load \\
CDB-M-IO & $160 \times 160$ & Internal shear span & Static load \\
CDB-M-MO & $160 \times 160$ & Mid-span & Static load \\
CDB-R-EO & $160 \times 160$ & External shear span & Repeated load \\
CDB-R-IO & $160 \times 160$ & Internal shear span & Repeated load \\
CDB-R-MO & $160 \times 160$ & Mid-span & Repeated load \\
\hline
\end{tabular}

* CDB: Continuous Deep Beam, M: Monotonic (static load), R: Repeated load, EO: External opening, IO: Internal opening, and MO: Mid-span openings (under load). 
Details and preparation of the test specimens. Details of test specimens are given in Figure 3 for continuous deep beams with 5-point bending. The arrangement of reinforcements consists of 3 \$12 $\mathrm{mm}$ rebars as longitudinal bottom reinforcement and $2 \$ 12 \mathrm{~mm}$ rebars as top reinforcement. In addition, $2 \$ 12 \mathrm{~mm}(\mathrm{~L}=0.7 \mathrm{~m})$ were provided at the negative region over the mid-span support. Furthermore, stirrups of $\$ 6 \mathrm{~mm}$ spaced each $70 \mathrm{~mm} \mathrm{c} / \mathrm{c}$ were used as shear reinforcement. In addition, $10 \$ 6 \mathrm{~mm}$ rebars were used as nominal skin reinforcement. Normal weight concrete with cylindrical compressive strength of about $23 \mathrm{MPa}$ was produced for casting the test specimens. The yield stress and ultimate strength for steel reinforcement were $510 \mathrm{MPa}$ and $625 \mathrm{MPa}$, respectively, for bar diameter of $6 \mathrm{~mm}$ and $650 \mathrm{MPa}$ and $730 \mathrm{MPa}$, respectively, for a bar diameter of $12 \mathrm{~mm}$.

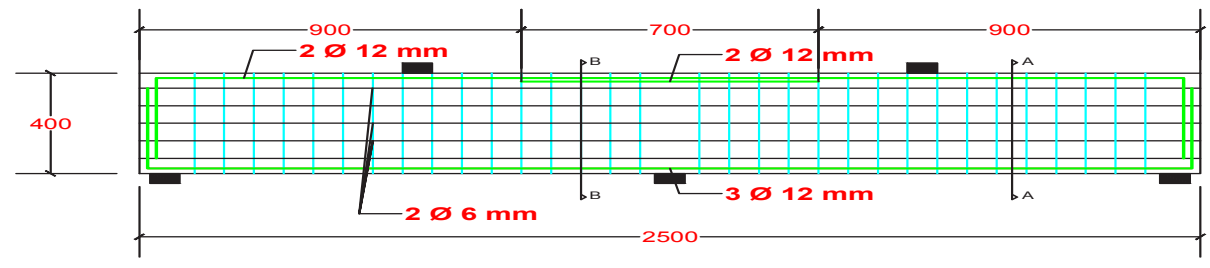

a. Beam CDB-Solid
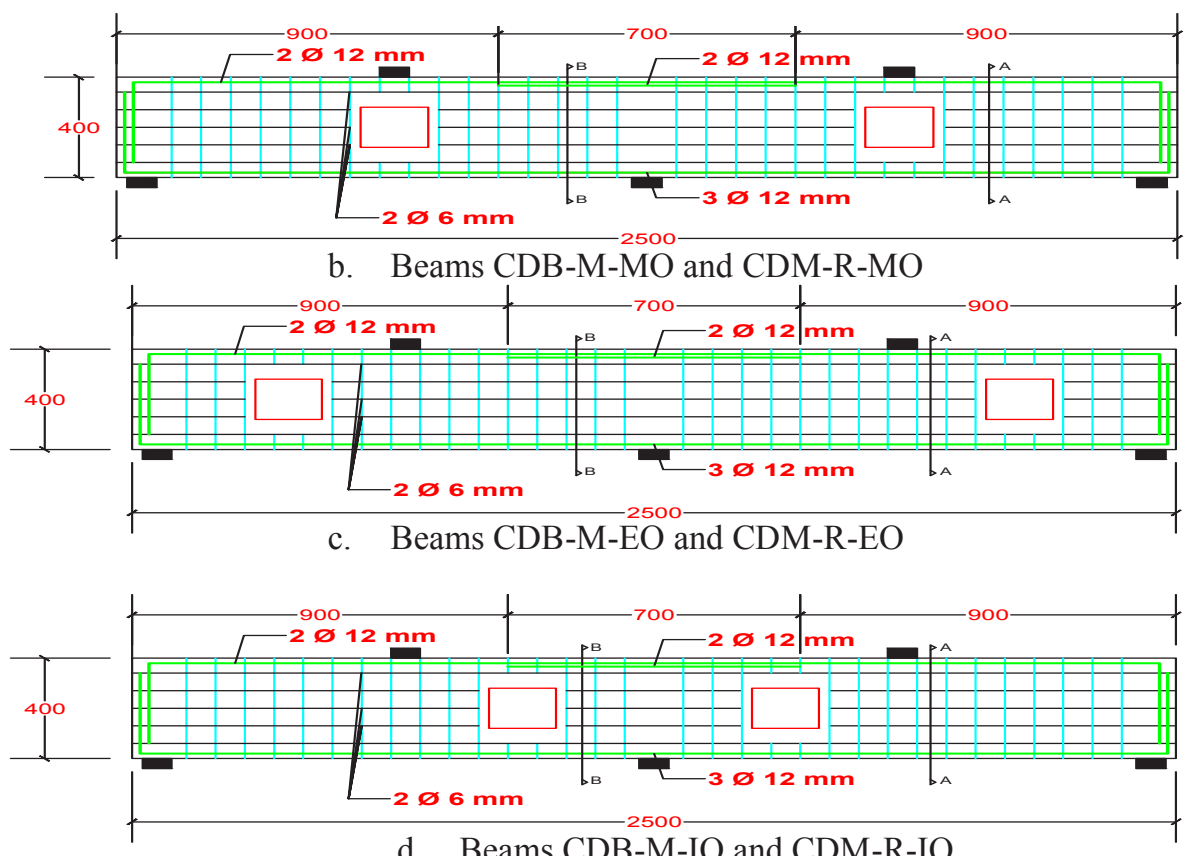

d. Beams CDB-M-IO and CDM-R-IO

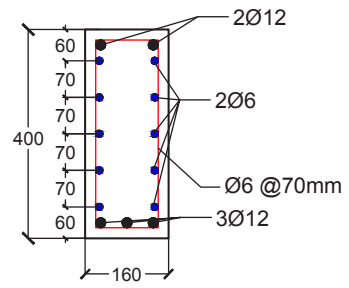

Section: A-A

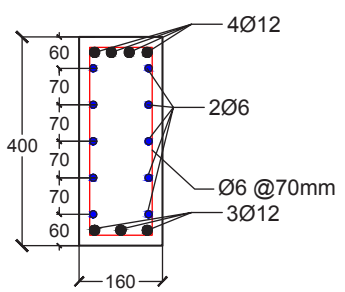

Section: B-B

Figure 3. Details of steel reinforcement for typically tested beam (all dimensions are in $\mathrm{mm}$ ).

Instrumentation and test setup. The test setup for beams with five-point bending and a shear span of $595 \mathrm{~mm}$ is shown in Figure 4. The load was applied with a $1000 \mathrm{kN}$ hydraulic jack and measured using a load cell $(2000 \mathrm{kN})$. Vertical deflections were measured using linear variable displacement transducers (LVDTs) for each span of beams. Three stages were involved in the application of repeated load. The minimum and maximum cyclic loads in the first stage were 30 percent and 70 percent, respectively, of the ultimate load of the similar beams under static load. The cyclic static load was applied until it reached $70 \%$ of the ultimate load, then it was unloaded to $30 \%$. A total of fifteen loading and unloading cycles were completed. In the second step, the load was released to zero after fifteen cycles of loading. Static loading was applied to the beams until they failed in the final step. 


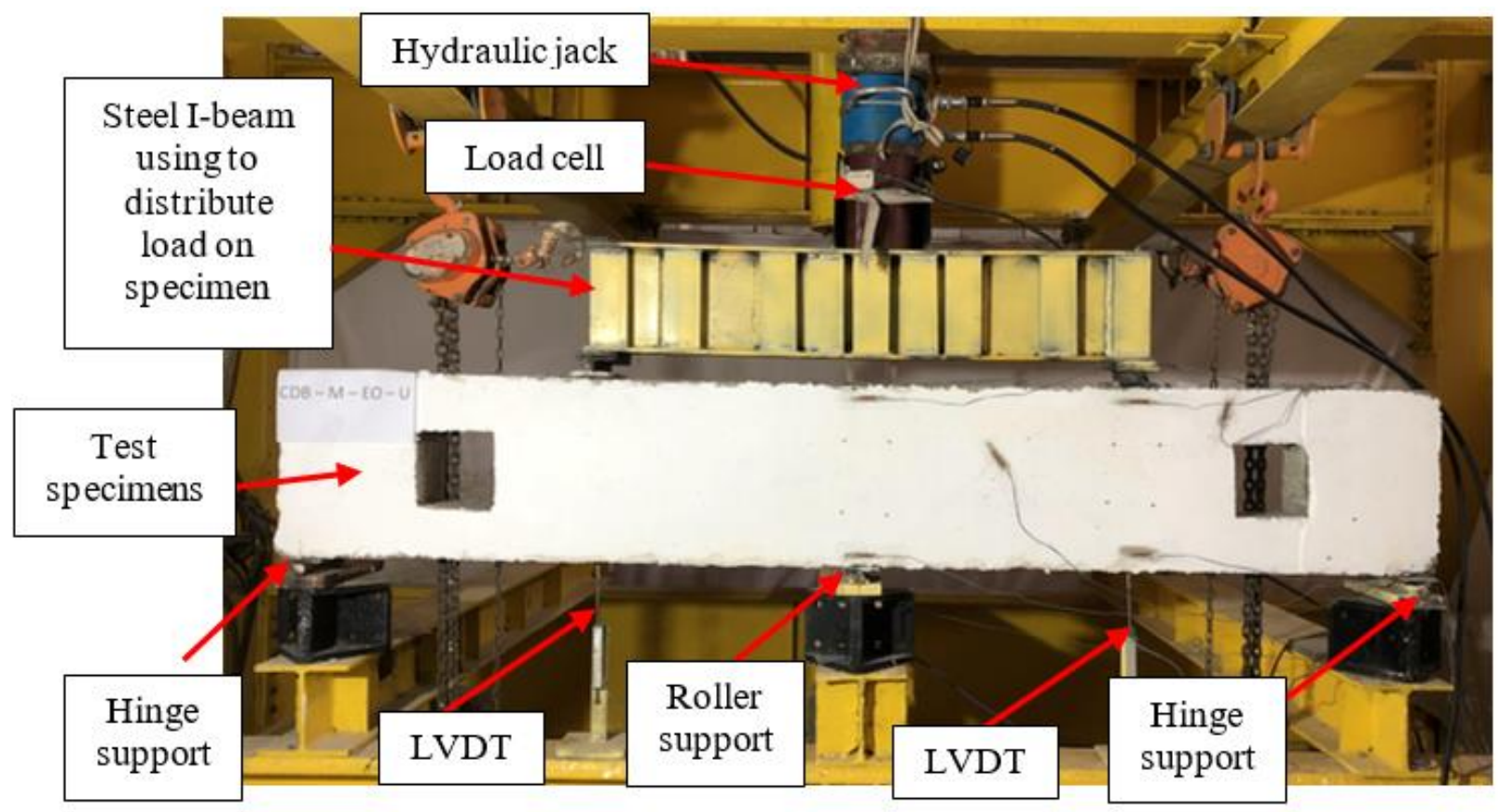

Figure 4. Test setup for typically tested beam.

\section{Description of Experimental Test Results}

Initial crack and mode of failure. The initial crack load was seen in the mid-span of each span of the continuous deep beam (i.e., flexural crack) for beam CDB-Solid during the experimental test. In the case of beams with large openings, the initial crack load was noticed at the opening corners and spread towards the loading and supporting points. Table 2 summarizes the cracking loads for tested beams. This table shows that the presence of large openings affects the behavior of continuous deep beams by decreasing the initial crack load compared to RCCDBs without opening (beam CDB-Solid). The percentages decrease in initial crack load were about 45,58 , and $30 \%$ for beams CDB-M-EO, CDB-M-IO, and CDB-M-MO, respectively, compared to beam CDB-Solid. These percentages were the same for beams subjected to limited cycles of repeated load.

Table 2. Cracking loads and mode of failure of tested beams.

\begin{tabular}{cccc}
\hline Specimen nomenclature & Location & Initial (first) crack load $(\mathbf{k N})$ & Mode of failure \\
\hline CDB-Solid & Solid & 200 & Shear failure \\
CDB-M-EO & External shear spans & 110 & Opening shear failure \\
CDB-M-IO & Internal shear spans & 85 & Opening shear failure \\
CDB-M-MO & Mid-spans & 140 & Bearing failure \\
CDB-R-EO & External shear spans & 110 & Opening shear failure \\
CDB-R-IO & Internal shear spans & 85 & Opening shear failure \\
CDB-R-MO & Mid-spans & 140 & Bearing failure \\
\hline
\end{tabular}

Figure 5 shows the crack pattern for all tested beams. It was observed from this figure that the mode of failure was a shear failure for beam CDB-Solid. While for beams CDB-M-MO and CDB-RMO the mode of failure was bearing failure at the top cord of openings. However, for beams with openings locating at external and internal shear spans (i.e., beams CDB-M-EO, CDB-M-IO, CDB-R$\mathrm{EO}$, and CDB-R-IO), the mode of failure was observed opening shear failure. 


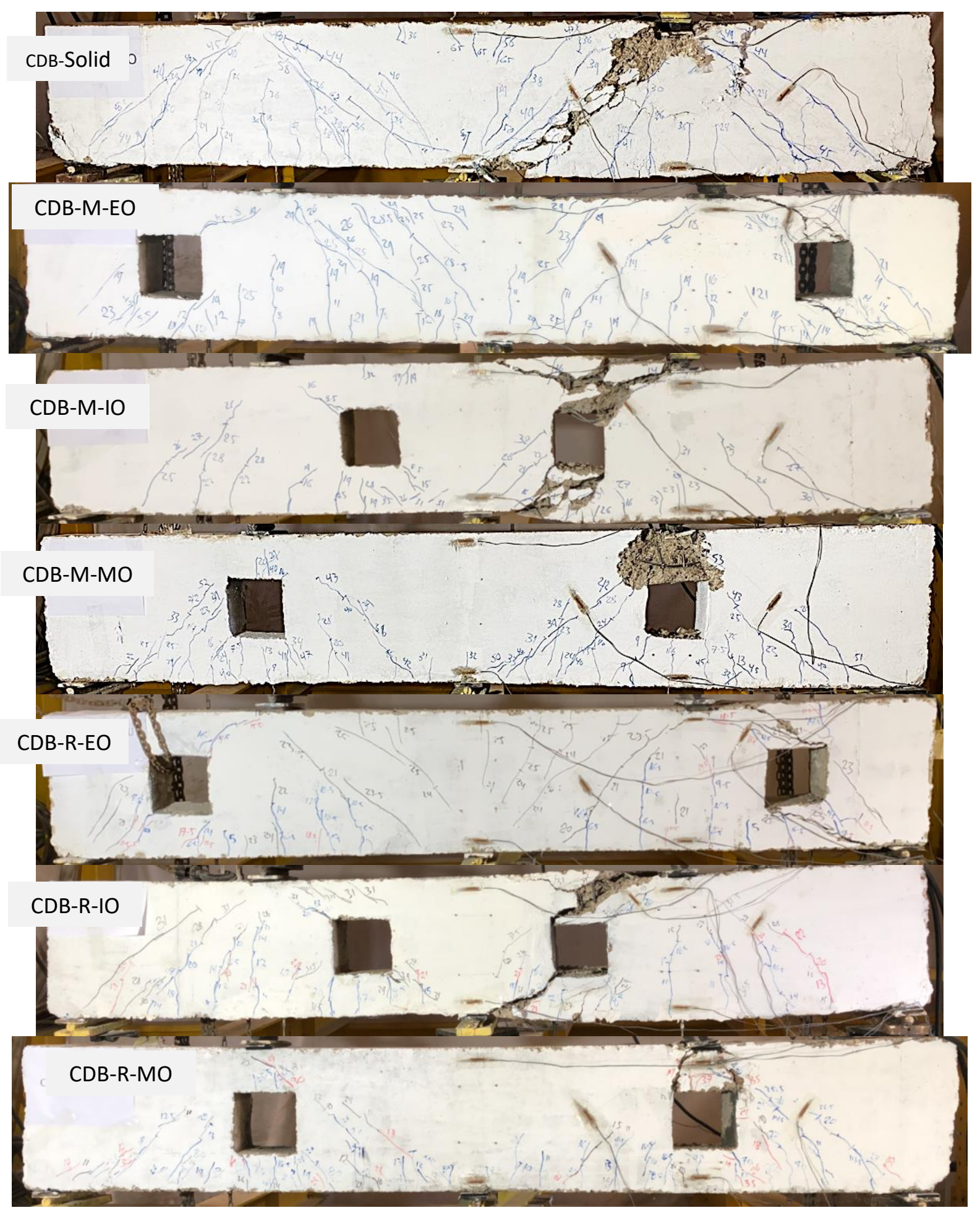

Figure 5. Crack pattern of tested beams at ultimate loads.

Load mid-span deflection response. Figure 6 shows the total applied load (P) with mid-span deflection of all test beams under static load. From this figure, it can be noticed that large openings reduce the stiffness and ultimate load and increase the deflections within the entire range of loading compared to beam CDB-Solid. In addition, Figure 7 to 9 shows the total applied load with midspan deflection for a beam with various locations of large openings under static and limited cycles repeated load. From this figure, it can be noticed that the application of limited cycles of repeated load leads to a decrease in the ultimate load compared with beams under static load. Table 3 summarizes the test results of the seven specimens in terms of key parameters of load-deflection curves. 
From this table, it was observed that the percentage decrease in ultimate loads for beams CDB-M-EO, CDB-M-IO, and CDB-M-MO was about 26, 36, and 23\%, respectively, compared to beam CDB-Solid. While, these percentages became about 30, 40, and $26 \%$ for beams CDB-R-EO, CDB-R-IO, and CDB-R-MO, respectively. However, when beams CDB-R-EO, CDB-R-IO, and CDB-R-MO compared to beams CDB-M-EO, CDB-M-IO, and CDB-M-MO, the percentages decrease in ultimate loads were about 5,6 , and $4 \%$, respectively. On the other hand, the presence of large openings leads to an increase in mid-span deflection by about 186,238 , and $27 \%$ for beams CDB-M-EO, CDB-M-IO, and CDB-M-MO, respectively, compared to beam CDB-Solid. While, in the case of repeated load, the percentage increase in mid-span deflection was about 191, 243, and $19 \%$ for beams CDB-R-EO, CDB-R-IO, and CDB-R-MO, respectively, compared to beam CDBSolid. It is worthwhile to mention that these percentages were calculated corresponding to the ultimate load of beam CDB-M-IO and CDB-R-IO. However, when beams CDB-R-EO, CDB-R-IO, and CDBR-MO compared to beams CDB-M-EO, CDB-M-IO, and CDB-M-MO, the percentages increase in mid-span deflection were about 18,5 , and $18 \%$, respectively at the same load level of ultimate load of beams under repeated load.

Table 3. Ultimate loads and mid-span deflections of tested beams.

\begin{tabular}{cccc}
\hline Specimen nomenclature & Location & $\begin{array}{c}\text { Ultimate load } \\
(\mathbf{k N})\end{array}$ & $\begin{array}{c}\text { Ultimate mid-span } \\
\text { deflection }\left(\Delta_{\mathbf{u}}\right)(\mathbf{m m})\end{array}$ \\
\hline CDB-Solid & Solid & 770 & 3.864 \\
CDB-M-EO & External shear spans & 570 & 4.142 \\
CDB-M-IO & Internal shear spans & 490 & 3.067 \\
CDB-M-MO & Mid-spans & 595 & 2.207 \\
CDB-R-EO & External shear spans & 540 & 4.067 \\
CDB-R-IO & Internal shear spans & 460 & 2.399 \\
CDB-R-MO & Mid-spans & 570 & 1.536 \\
\hline
\end{tabular}

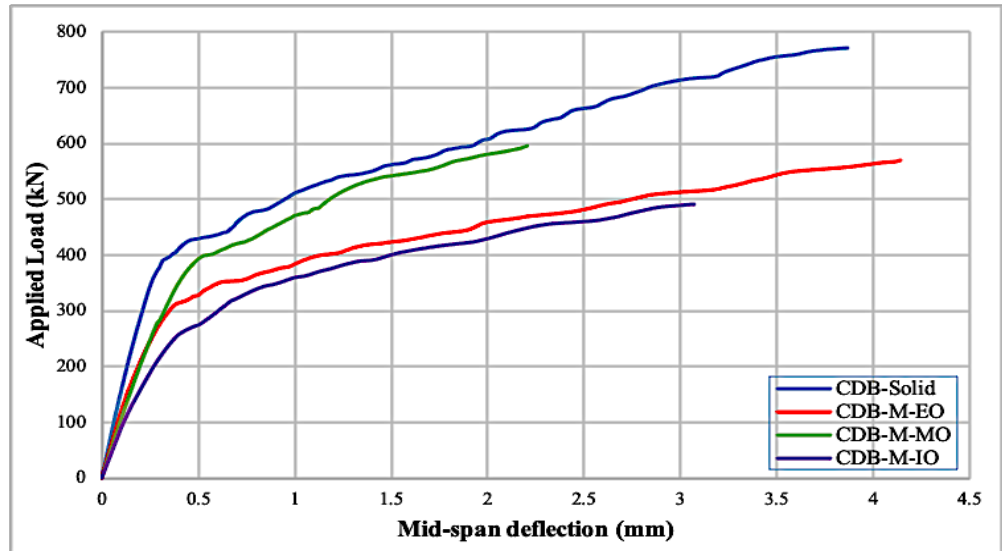

Figure 6. Load mid-span deflection for tested RCCDBs with openings under static load.

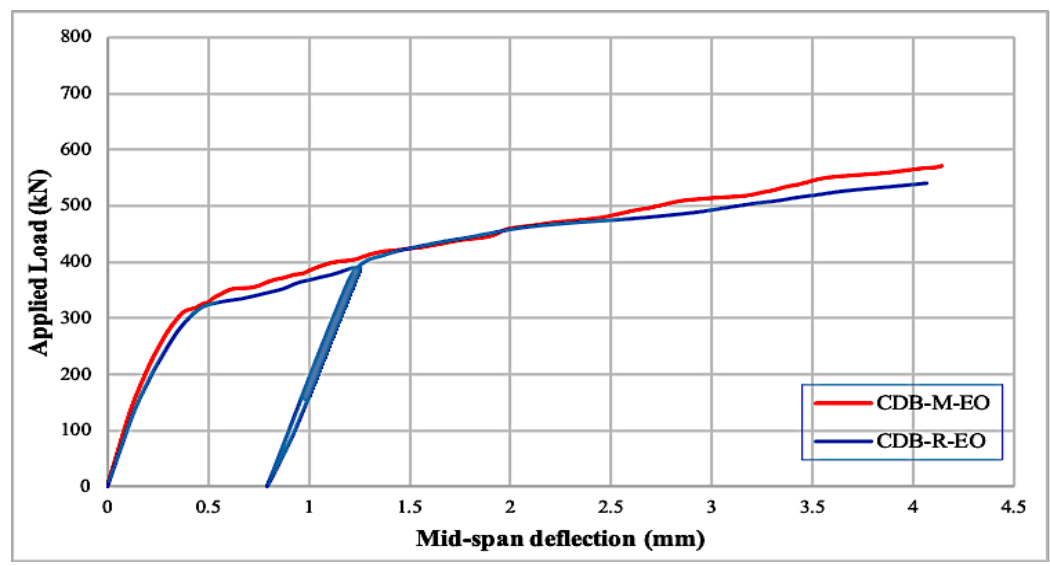

Figure 7. Load mid-span deflection for tested RCCDBs with openings located at external shear spans. 


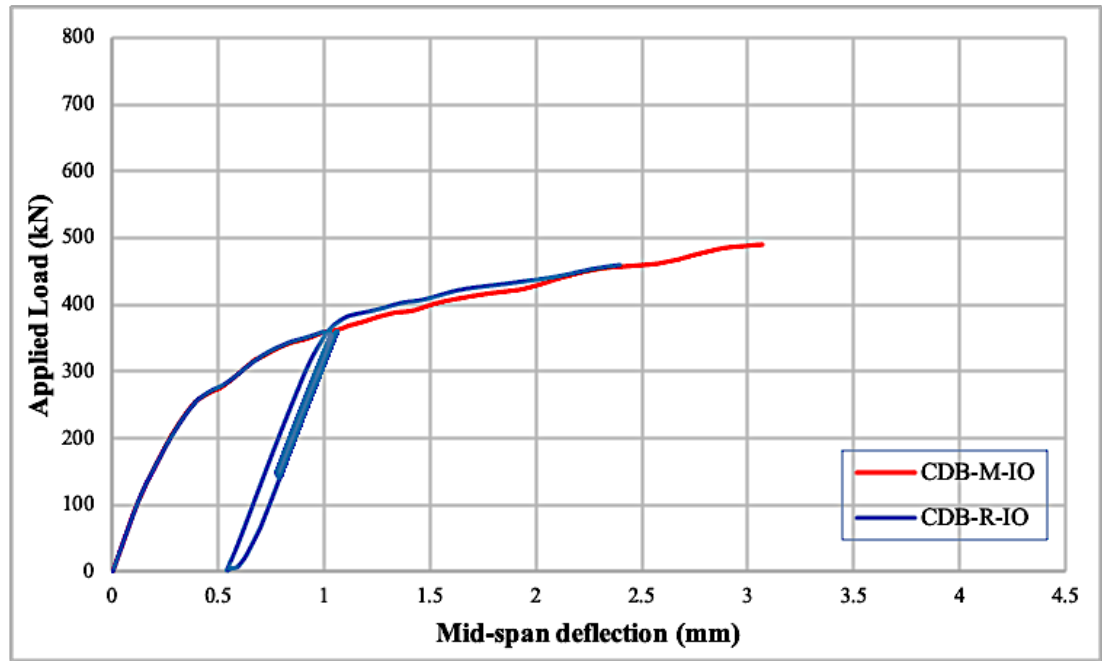

Figure 8. Load mid-span deflection for tested RCCDBs with openings located at internal shear spans.

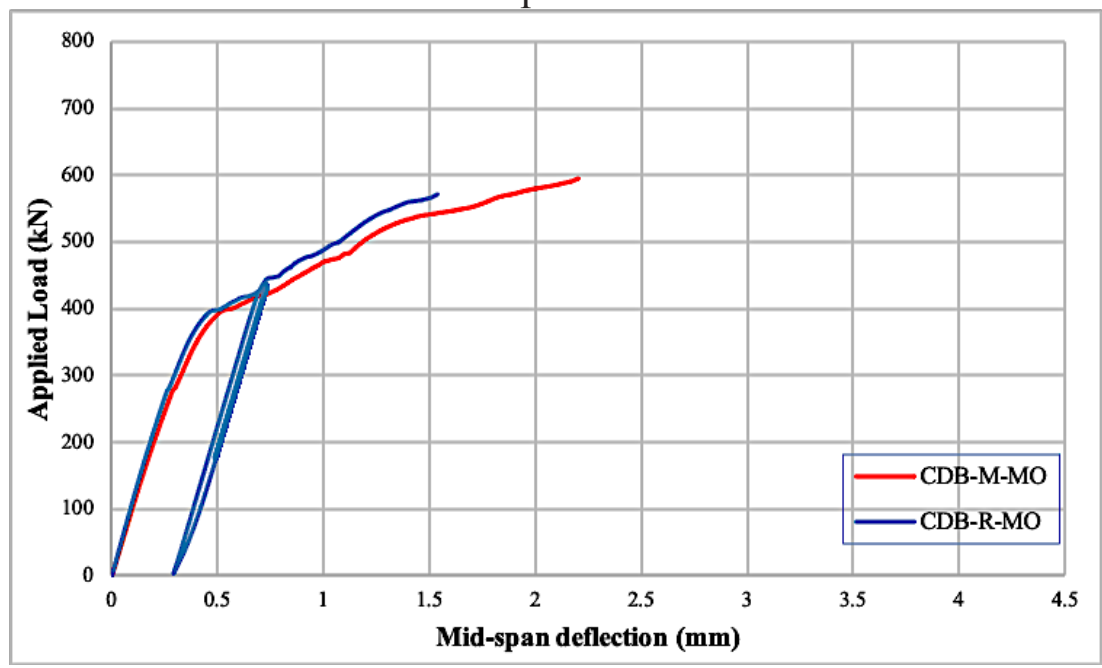

Figure 9. Load mid-span deflection for tested RCCDBs with openings located at mid-spans.

\section{Conclusions}

The following conclusions can be drawn from this research work.

- Large openings in RCCBD lead to a decrease in the ultimate load and an increase in mid-span deflection.

- From the experimental test, the existence of large openings within exterior or interior shear spans caused a reduction in ultimate load by about $26 \%$ and $36 \%$ compared with beam without openings. However, when opening located within mid-span region, the percentage decrease in ultimate load became about $23 \%$.

- For beams under limited cycles of repeated load, it was observed that the reduction in ultimate load was about 5,6 , and $4 \%$ for beams with opening locating at the exterior, interior, and midspan, respectively, compared to beam under static load.

\section{References}

[1] Wight, J.K. and J.G. MacGregor, 2020. Reinforced concrete mechanics and design.

[2] Kong, F.K., Sharp, G.R., Appleton, S.C., Beaumont, C.J. and Kubik, L.A., 1978. Structural idealization for deep beams with web openings: further evidence. Magazine of Concrete Research, 30(103), pp.89-95.

[3] Kong, F.K. and Sharp, G.R., 1977. Structural idealization for deep beams with web openings. Magazine of Concrete Research, 29(99), pp.81-91. 
[4] ACI 318-19M, 2019, Building code requirements for structural concrete and commentary. American Concrete Institute.

[5] Nie, J.G., Pan, W.H., Tao, M.X. and Zhu, Y.Z., 2017. Experimental and numerical investigations of composite frames with innovative composite transfer beams. Journal of Structural Engineering, 143(7), p.04017041.

[6] Mansur, M.A. and Tan, K.H., 1999. Concrete beams with openings: analysis and design (Vol. 20). CRC Press.

[7] Khalaf, M.R. and Al-Ahmed, A.H.A., 2020, December. Shear strength of reinforced concrete deep beams with large openings strengthened by external prestressed strands. In Structures (Vol. 28, pp. 1060-1076). Elsevier.

[8] Rahim, N.I., Mohammed, B.S., Al-Fakih, A., Wahab, M.M.A., Liew, M.S., Anwar, A., and Amran, Y.H., 2020. Strengthening the structural behavior of web openings in RC deep beam using CFRP. Materials, 13(12), p.2804.

[9] Hassan, H.M., Arab, M.A.E.S. and Ismail el-kassas, A., 2019. Behavior of high strength self compacted concrete deep beams with web openings. Heliyon, 5(4), p.e01524.

[10] Gergely, V., Pop, M., Campian, C. and Chira, N., 2019, August. Finite element modelling of different strengthening strategies for reinforced concrete deep beams. In IOP Conference Series: Materials Science and Engineering (Vol. 586, No. 1, p. 012023). IOP Publishing.

[11] Fatehi Makki, R., Talib Jassem, A. and Abd Al-Latef Jassem, H., 2019. Behavior of ReactivePowder Concrete Deep Beams with CFRP-Strengthened Openings. Practice Periodical on Structural Design and Construction, 24(4), p.04019016.

[12] Almusallam, T., Al-Salloum, Y., Elsanadedy, H., Alshenawy, A. and Iqbal, R., 2018. Behavior of FRP-strengthened RC beams with large rectangular web openings in flexure zones: experimental and numerical study. International Journal of Concrete Structures and Materials, 12(1), pp.1-28.

[13] Al-Ahmed, A.H.A. and Khalaf, M.R., 2017. Openings effect on the performance of reinforced concrete deep beams. Proceeding of the First MoHESR and HCED Iraqi Scholars Conference in Australasia.

[14] Al-Bayati, N., Muhammad, B. and Faek, M., 2018. Strengthening of self-compacting reinforced concrete deep beams containing circular openings with CFRP. In MATEC Web of Conferences (Vol. 162, p. 04015). EDP Sciences.

[15] Al-Ahmed, A.H.A. and Khalaf, M.R., 2017. Behavior of Reinforced Concrete Deep Beams with Large Openings Strengthened by External Post-Tensioning Strands. International Journal of Science and Research (IJSR), 6(9). 